\title{
p53 and the Hypoxia-induced Apoptosis of Cultured Neonatal Rat Cardiac Myocytes
}

\author{
Xilin Long, Marvin O. Boluyt, Maria de Lourdes Hipolito, Martha S. Lundberg, Jing-Sheng Zheng, Lydia O’Neill, \\ Corrado Cirielli, ${ }^{\star}$ Edward G. Lakatta, and Michael T. Crow \\ Laboratory of Cardiovascular Science, Gerontology Research Center, National Institute on Aging, National Institutes of Health, \\ Baltimore, Maryland 21224; and *Laboratorio di Patologia Vascolare, Istituto Dermopatico dell'Immacolata, Rome, Italy
}

\begin{abstract}
Myocyte cell loss is a prominent and important pathogenic feature of cardiac ischemia. We have used cultured neonatal rat cardiac myocytes exposed to prolonged hypoxia as an experimental system to identify critical factors involved in cardiomyocyte death. Exposure of myocytes to hypoxia for $48 \mathrm{~h}$ resulted in intranucleosomal cleavage of genomic DNA characteristic of apoptosis and was accompanied by increased p53 transactivating activity and protein accumulation. Expression of p21/WAF-1/CIP-1, a well-characterized target of p53 transactivation, also increased in response to hypoxia. Hypoxia did not cause DNA laddering or cell loss in cardiac fibroblasts. To determine whether the increase in p53 expression in myocytes was sufficient to induce apoptosis, normoxic cultures were infected with a replication-defective adenovirus expressing wild-type human p53 (AdCMV.p53). Infected cells expressed high intracellular levels of p53 protein and exhibited the morphological changes and genomic DNA fragmentation characteristic of apoptosis. In contrast, no genomic DNA fragmentation was observed in myocytes infected with the control virus lacking an insert (AdCMV.null) or in cardiac fibroblasts infected with AdCMV.p53. These results suggest that the intracellular signaling pathways activated by p53 might play a critical role in the regulation of hypoxia-induced apoptosis of cardiomyocytes. (J. Clin. Invest. 1997. 99:2635-2643.) Key words: p53 • apoptosis • cardiomyocytes $\bullet$ hypoxia $\bullet$ ischemia
\end{abstract}

\section{Introduction}

Myocardial ischemia leads to cardiac cell loss and scar formation, resulting in reduced pumping capacity which eventually leads to congestive heart failure and death (1). Cell loss is due predominantly to the death of cardiomyocytes, and experiments in various animal models indicate that this loss can occur by both apoptotic and necrotic mechanisms. For example, in vivo experiments on rabbit heart have reported that the cell death that follows the reperfusion of ischemic areas is due primarily to apoptosis, while that which occurs during prolonged ischemia is due

Address correspondence to Dr. Michael T. Crow, Laboratory of Cardiovascular Science, Gerontology Research Center, National Institute on Aging, NIH, 4940 Eastern Ave., Baltimore, MD 21224. Phone: 410-558-8207; FAX: 410-558-8150; E-mail: crowm@grc.nia. nih.gov

Received for publication 7 March 1996 and accepted in revised form 10 March 1997.

The Journal of Clinical Investigation

Volume 99, Number 11, June 1997, 2635-2643 primarily to necrosis (2). On the other hand, studies in the rat indicate that cell death from prolonged ischemia can occur by both apoptotic and necrotic mechanisms (3).

Apoptosis was originally described as a physiological process for selective cell removal through programmed selfdestruction. It is characterized by condensation of the cytoplasm, loss of plasma membrane microvilli, segmentation of the nucleus, and extensive degradation of chromosomal DNA into oligomers of $\sim 180$ bp (4). As a physiological mechanism for selective cell loss, apoptosis plays an important role in embryogenesis and normal tissue turnover (5). However, failure to regulate apoptosis, has been associated with various degenerative, hyperproliferative, and autoimmune diseases (6).

Multiple pathways exist for inducing apoptosis. Although originally identified as a tumor suppressor gene, the inactivation of which is a common event in the development of human neoplasia (7), the product of the p53 gene has been shown recently to play an important role in the regulation of apoptosis in a number of different cell lines. For example, introduction of p53 in the myeloid leukemia cell line M1, which has no endogenous p53 expression, induces apoptosis (8), while in other myeloid cell lines expression of a dominant negative p53 gene can prevent the apoptosis that results from growth factor withdrawal (9). The level of p53 expression has also been shown to increase after treatments which result in increased DNA damage (10). Depending on the cell type, elevated p53 after DNA damage can result in either growth arrest or apoptosis $(11,12)$.

One important aspect of ischemia is hypoxia. Recent studies have shown that hypoxia of cultured neonatal cardiomyocytes causes morphological and biochemical changes characteristic of cell death by apoptosis (13). We show here that prolonged hypoxia of neonatal cardiomyocytes results in substantial cell loss by apoptosis and is associated with increased p53 expression and transactivating ability. Indeed, overexpression of p53 in normoxic cardiomyocytes is itself sufficient to induce apoptotic cell death, suggesting that p53 or its downstream targets play an important role in regulating cell death in this mostly postmitotic cell population.

\section{Methods}

Cell cultures and treatments. Hearts from 1-3-d-old Wistar rats were removed, and the ventricles were separated from attached vessels and atria and then trisected. Neonatal ventricular myocytes were prepared from digestion of these tissue fragments and cultured as previously described (14). For statistical purposes, each culture preparation was defined as an independent experiment. Myocytes were purified on a discontinuous Percoll gradient and myocyte purity was monitored by staining with antibodies to cardiac $\alpha$-actin or cardiac myosin heavy chains as described previously (14). Myocyte purity averaged $94 \pm 4 \% 48 \mathrm{~h}$ after plating. Myocytes were cultured on gelatincoated tissue culture plates at an initial density of $10^{5} \mathrm{cells} / \mathrm{cm}^{2}$. Under these sparse plating conditions, the percentage of cells that con- 
tracted at a rate $>10 \mathrm{bpm}$ was $4.0 \pm 1.1 \%$ for both untreated (normoxic) or hypoxic-treated and Ad.CMVp53-infected ${ }^{1}$ cells.

During the initial $24 \mathrm{~h}$ after plating, myocytes were cultured in media consisting of four parts (by volume) of DME containing 4.5 g/liter glucose and one part medium 199 (Earle's salts; GIBCO BRL, Gaithersburg, MD) supplemented with $10 \%$ preselected horse serum, $5 \%$ heat-inactivated FBS, penicillin $(100 \mathrm{U} / \mathrm{ml})$, and streptomycin $(100 \mathrm{mg} / \mathrm{ml})$. After that, both the horse and fetal calf serum were removed and replaced with $1 \mu \mathrm{mol} / \mathrm{liter}$ insulin, $5 \mu \mathrm{mol} /$ liter transferrin, and $10 \mathrm{nmol} /$ liter selenium. In the initial series of experiments, cultured myocytes were maintained in high levels of bromodeoxyuridine $\left(10^{-4} \mathrm{M}\right)$ to inhibit cell replication of the small percentage of fibroblasts that was present. However, neither the presence of bromodeoxyuridine nor contaminating fibroblasts affected the results presented.

Fibroblasts were isolated from the neonatal heart by taking cells from the $1.050 \mathrm{~g} / \mathrm{ml}$ band and passaging them three times in culture. Immunocytostaining with antibodies to cardiac $\alpha$-actin or sarcomeric myosin heavy chains identified no positive cells in such cultures. Cardiac fibroblasts were cultured in the myocyte media containing $10 \%$ fetal calf serum.

To expose the cells to hypoxia, they were placed in a Plexiglas chamber and a constant stream of water-saturated $95 \% \mathrm{~N}_{2} / 5 \% \mathrm{CO}_{2}$ was maintained over the culture. The partial pressure of oxygen $\left(\mathrm{PO}_{2}\right)$ of the culture media under these conditions was measured with an oxygen electrode and a dual channel differential oxygen electrode amplifier (Instech Laboratories, Plymouth, PA). These measurements indicated that the $\mathrm{PO}_{2}$ decreased in an exponential fashion after the culture dish was placed in the equilibrated chamber and a steady state $\mathrm{PO}_{2}$ of $<15$ Torr was achieved after $8 \mathrm{~h}$ of gas flow.

Analysis of DNA fragmentation. Genomic DNA was isolated and detected as described previously (15). Myocytes from 4-5 100$\mathrm{mm}$ dishes were harvested by trypsinization in $0.25 \%$ trypsin (GIBCO $\mathrm{BRL}) / 1 \mathrm{mM}$ EDTA for $5 \mathrm{~min}$ at $37^{\circ} \mathrm{C}$ and collected in a $1.5-\mathrm{ml}$ conical tube by low-speed centrifugation. The cell pellet was then resuspended in $0.5 \mathrm{ml}$ of lysis buffer $(10 \mathrm{mM}$ Tris- $\mathrm{HCl}, \mathrm{pH} 8.0,10 \mathrm{mM}$ EDTA, pH 8.0, $75 \mathrm{mM} \mathrm{NaCl}, 0.5 \%$ SDS, and $0.15 \mathrm{mg} / \mathrm{ml}$ proteinase $\mathrm{K})$ and incubated at $50^{\circ} \mathrm{C}$ for $3 \mathrm{~h}$. The digestion was then subjected to centrifugation for $20 \mathrm{~min}$ at $14,000 \mathrm{rpm}$. The supernatant was removed and nucleic acids were precipitated by adding $0.1 \mathrm{vol}$ of $5 \mathrm{M}$ $\mathrm{NaCl}$ and $2.5 \mathrm{vol}$ ice-cold ethanol and incubating at $-20^{\circ} \mathrm{C}$ for $20 \mathrm{~min}$. The nucleic acid pellet was then resuspended in $0.5 \mathrm{ml}$ of TE $(10 \mathrm{mM}$ Tris-HCl [pH 8], $1 \mathrm{mM}$ EDTA) containing $0.2 \mathrm{mg} / \mathrm{ml}$ RNAse A (Sigma Chemical Co., St. Louis, MO) for $1 \mathrm{~h}$ at $37^{\circ} \mathrm{C}$. The digestion was then extracted with an equal volume of phenol- $\mathrm{CHCl}_{3}$, then $\mathrm{CHCl}_{3}$ alone, and the nucleic acids in the aqueous phase were precipitated with ethanol at $-20^{\circ} \mathrm{C}$ for $20 \mathrm{~min}$.

TUNEL analysis of cultured myocytes and fibroblasts was performed with a commercially available kit for detecting end-labeled DNA according to the manufacturer's instructions (Trevigen, Inc., Gaithersburg, MD).

Myocyte transfection and the $p 53$ transactivation assay. Myocyte cultures were transfected using a modification of the calcium phosphate method (16). Cells were plated in 6-well plates $\left(10 \mathrm{~cm}^{2}\right)$ at a density of $2.5 \times 10^{4}$ cells $/ \mathrm{cm}^{2}$ in serum-containing media containing

1. Abbreviations used in this paper: AdCMV.NLS $\beta$ gal, recombinant replication of defective adenovirus in which a recombinant bacterial $\beta$-galactosidase gene containing an eukaryotic nuclear translocation signal (NLS) is under the transcriptional control of the cytomegalovirus long terminal repeat; AdCMV.null, recombinant replication defective adenovirus containing no gene in its cloning cassette; AdCMV.p53, recombinant replication defective adenovirus in which the human wild-type p53 is under the transcriptional control of the cytomegalovirus long terminal repeat; $\mathrm{p} 21 / \mathrm{WAF}-1 / \mathrm{CIP}-1$, p21/wild-type $\mathrm{p} 53$ activated fragment $1 /$ cyclin kinase inhibitor protein-1; SST, sequencespecific transactivation.
$10^{-5} \mathrm{M}$ bromodeoxyuridine (Sigma Chemical Co.) for $12-18 \mathrm{~h}$. Transfection was performed in serum-containing media with the calcium phosphate-DNA precipitate left in contact with the cells overnight. The cells were then rinsed with serum-free media and hypoxic or normoxic conditions were introduced in a serum-free environment. A total of $4 \mu \mathrm{g} /$ well ( $1 \mathrm{ml}$ media) DNA was transfected, with $2 \mu \mathrm{g}$ of reporter construct and $0.05 \mu \mathrm{g}$ pRSV- $\beta$ gal (used to control for difference in transfection efficiency). Where needed to maintain a constant total amount of transfected DNA, filler DNA consisted of the pGL2-basic plasmid (Promega Corp., Madison, WI). p53 transactivating ability was assessed from the activity of the transfected reporter, PG13-luc, which carries the luciferase reporter gene driven by the minimal polyoma promoter and 13 copies of the wild-type p53binding site. For controls, cells were transfected with MG15-luc, a luciferase reporter plasmid driven by the minimal polyoma promoter and 15 copies of a mutated p53-binding site (17), or with PG13-luc and pSVKH215 (18), the latter being an expression vector for a mutant p53 that acts as a dominant negative for sequence-specific transactivation by $\mathrm{p} 53$.

RNA isolation and analysis. Total RNA was isolated from cultured myocytes using the guanidinium isothiocyanate method (19). The RNA was prepared for gel electrophoresis by denaturation in formamide and formaldehyde as described previously (14) and equal amounts $(10 \mu \mathrm{g} / \mathrm{lane})$ were size-fractionated by electrophoresis through $1 \%$ agarose gels containing $3 \%$ formaldehyde. The fractionated RNA was electrophoretically transferred to nylon membranes, cross-linked by ultraviolet irradiation $(120 \mathrm{~mJ})$, and then hybridized at $63.5^{\circ} \mathrm{C}$ with ${ }^{32} \mathrm{P}$-radiolabeled oligonucleotides or cDNA probes as described (20). The probe for $\mathrm{p} 21 / \mathrm{WAF} 1 / \mathrm{CIP} 1$ was a cDNA for the mouse gene and radiolabeled using the random priming method (21). The probe for $18 \mathrm{~S}$ rRNA was a synthetic oligonucleotide. Its sequence and method for radiolabeling has been described previously (22).

Adenoviruses and adenoviral infection of neonatal cardiomyocytes. AdCMV.p53 was generously provided by Dr. Bert Vogelstein (Johns Hopkins Oncology Center, Baltimore, MD). It is a replication-defective adenovirus containing the cDNA for human wild-type p53 driven by the cytomegalovirus promoter (17). The virus was amplified in 293 cells (American Type Culture Collection, Rockville, MD) using standard procedures (23). AdCMV.NLS $\beta$ gal and AdCMV.null are replication-deficient adenoviruses encoding bacterial $\beta$-galactosidase (AdCMV.NLSßgal) or containing an empty expression cassette (AdCMV.null), respectively.

Adenoviral infection of cultured neonatal cardiomyocytes was performed $48 \mathrm{~h}$ after isolation from the animal and initial plating in gelatin-coated tissue culture dishes using a modification of a previously published procedure (24). Infection was performed in a small amount of serum-free media ( $1 \mathrm{ml} / 35-\mathrm{mm}$ plate $)$ at an moi of 10 for $1.5 \mathrm{~h}$. Additional serum-free media were added $(1.5 \mathrm{ml} / 35-\mathrm{mm}$ plate $)$ and incubation continued for $48 \mathrm{~h}$. The efficiency of expression in myocytes was assessed by infection with AdCMV.NLS $\beta$ gal. A range of 10-100 moi resulted in $>95 \%$ infection after $48 \mathrm{~h}$; beyond 100 moi, there was observable cell loss due to necrosis.

Immunoblotting and immunocytochemistry. For each time point or manipulation, protein extracts were prepared from two $100-\mathrm{mm}$ plates for Western blotting. Cells were lysed at $4^{\circ} \mathrm{C}$ in modified RIPA buffer consisting of $150 \mathrm{mM} \mathrm{NaCl}, 10 \mathrm{mM}$ Tris-HCl, $\mathrm{pH} 7.4,1 \mathrm{mM}$ EDTA, 1\% Triton X-100, 1\% deoxycholic acid, $1 \mathrm{mM}$ PMSF, and 10 $\mu \mathrm{g} / \mathrm{ml}$ each of leupeptin and aprotinin. Equal amounts of protein (20$30 \mu \mathrm{g}$ ) were size-fractionated by electrophoresis on $10 \%$ polyacrylamide SDS gels and electrotransferred to polyvinylidene fluoride membranes using a semi-dry transfer system (Bio-Rad Labs, Richmond, CA). The membrane was blocked with $10 \%$ nonfat dry milk in PBS for $2 \mathrm{~h}$ at room temperature or overnight at $4{ }^{\circ} \mathrm{C}$ and then incubated at $4^{\circ} \mathrm{C}$ overnight with monoclonal antibodies to p53 (Pab 421 to detect rat p53 in hypoxia-treated cells or DO-1 to specifically detect human p53 protein in AdCMV.p53 infected cells) (Calbiochem Corp., San Diego, CA). Antigen-antibody complexes were visualized by chemiluminescence (Amersham Corp., Arlington, IL) after incubating the 
kbp

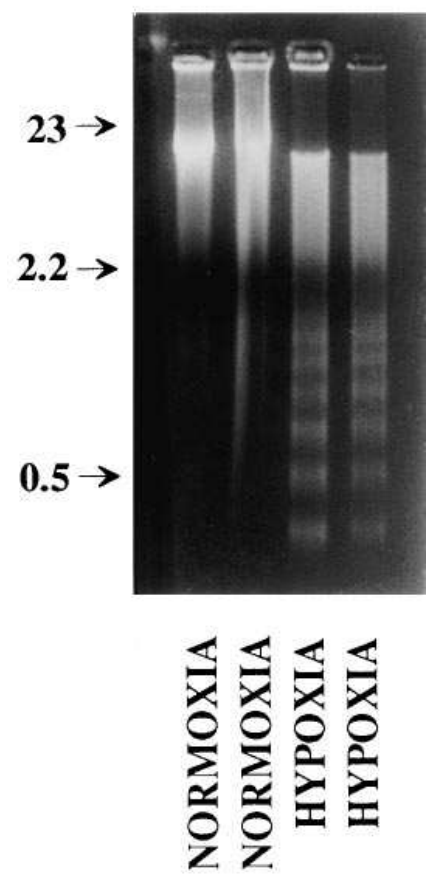

HOURS 48724872
Figure 1. Chronic exposure to hypoxia results in fragmentation of cardiomyocyte DNA. DNA isolated from cultures of neonatal cardiac myocytes exposed to normoxic

(NORMOXIA) or hypoxic (HYPOXIA) conditions for 48 or $72 \mathrm{~h}$. Electrophoresis of genomic DNA reveals a fragmentation pattern characteristic of apoptosis only in DNA isolated from hypoxia-treated cultures. Two independent results characteristic of a total of five independent experiments.

membrane for $4 \mathrm{~h}$ at room temperature with anti-mouse IgG conjugated to horseradish peroxidase. The relative intensities of the luminescent signals captured on $\mathrm{x}$-ray film were quantified by densitometry (Personal densitometer; Molecular Dynamics, Sunnyvale, CA).

For the cellular colocalization of $\mathrm{p} 53$ protein and end-labeled DNA, myocytes were plated on Permanox plastic chamber slides (Lab-tek, Naperville, IL) and fixed for $20 \mathrm{~min}$ at room temperature with $3.7 \%$ paraformaldehyde in PBS, after treatment or infection. The slides were then processed for TUNEL staining (Trevigen, Inc.) by incubating in TDT buffer (140 mM sodium cacodylate, $1 \mathrm{mM} \mathrm{CoCl}$, and $30 \mathrm{mM}$ Tris- $\mathrm{HCl}, \mathrm{pH}$ 7.2) for $5 \mathrm{~min}$. Terminal transferase and biotin-16-dUTP were then added $(550 \mathrm{U} / \mathrm{ml}$ and $10 \mu \mathrm{g} / \mathrm{ml}$, respectively) and the slides were incubated at $37^{\circ} \mathrm{C}$ for $1 \mathrm{~h}$. The reaction was stopped by rinsing the slides in $300 \mathrm{mM} \mathrm{NaCl}$ containing $30 \mathrm{mM}$ sodium citrate. Slides were then washed two times with distilled water and rinsed in PBS. Nonspecific binding was blocked by incubating in $2 \%$ BSA in PBS for $20 \mathrm{~min}$. The slides were then incubated with a monoclonal antibody to human p53 (DO-1; Santa Cruz Biotechnology, Santa Cruz, CA) for $2 \mathrm{~h}$ at room temperature and then with anti-mouse $\mathrm{IgG}$ conjugated to Texas red (to detect p53) and with avidin conjugated to fluorescein (to detect end-labeled DNA). Slides were imaged on a confocal microscope (LSM 410; Carl Zeiss, Inc., Thornwood, NY).

\section{Results}

Cultured neonatal rat cardiac myocytes exposed to hypoxia for $48 \mathrm{~h}$ exhibited an intranucleosomal DNA cleavage characteristic of apoptosis, while normoxic time-matched controls showed no genomic DNA degradation or fragmentation (Fig. 1). This result is similar to that previously shown by Tanaka and colleagues (13). Increased end-labeling of DNA in individual hypoxia-treated myocytes as detected by the TUNEL method is shown in Fig. $2 B$ and the time course of the changes

in end-labeling in normoxic and hypoxic myocytes is shown in Fig. $2 C$. Significant increases in the number of end-labeled (apoptotic) cells occurred 12-24 h after hypoxia and rose to include $>60 \%$ of the remaining cells in the culture at $48 \mathrm{~h}$ after placement in the hypoxia chamber. Myocytes maintained under normoxic conditions for $48 \mathrm{~h}$ showed minimal (11.3土 $1.5 \%)$ nuclear end-labeling. The results demonstrate that hypoxia markedly accelerates cardiomyocyte apoptosis.

Under the same hypoxic conditions, the activity of a transfected p53-dependent luciferase reporter plasmid, PG13-luc, containing a minimal polyoma promoter driven by 13 wildtype p53 DNA binding sites, increased $\sim 3.5$-fold over the basal level of expression in normoxic myocytes (Fig. 3). This increase in reporter expression represented increased p53 sequence-specific transactivation (SST), as demonstrated by the fact that there was no change with hypoxia in luciferase activity in a reporter gene containing the minimal polyoma promoter driven by 15 mutated p53-DNA binding sites (MG-15-luc) and that cotransfection of an expression vector for a mutant p53 protein ( $\mathrm{pSVKH} 215)$, which acts as a dominant negative inhibitor for SST, suppressed reporter activity (Fig. 3). Another indicator of increased p53 SST in the hypoxia-treated myocytes was the elevation in $\mathrm{p} 21 / \mathrm{WAF}-1 /$ cip-1 mRNA levels,
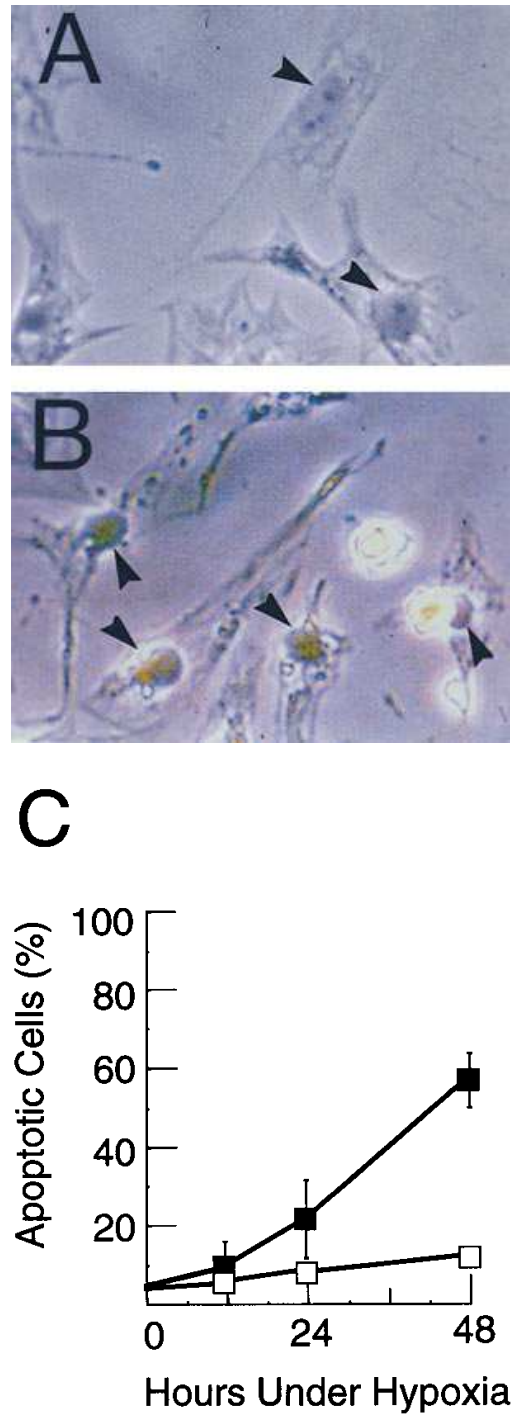

Figure 2. Chronic exposure to hypoxia results in increased end-labeling of DNA. ( $A$ and $B$ ) Photomicrographs of control (normoxia) $(A)$ and hypoxia-treated $(B)$ cardiomyocytes stained for end-labeled DNA by the TUNEL technique using horseradish peroxidase and diaminobenzidine for detection. Nuclei are indicated by the arrowheads. Brown nuclei contain elevated end-labeled DNA. (C) Quantitative analysis of percent cells undergoing apoptosis as measured by the TUNEL technique. Data were collected at $0,12,24$, and $48 \mathrm{~h}$ after exposure to hypoxia (ם). Normoxia ( $\square$ ) time points were collected in parallel cultures maintained under atmospheric oxygen levels. Data represent the average from at least four independent experiments. 


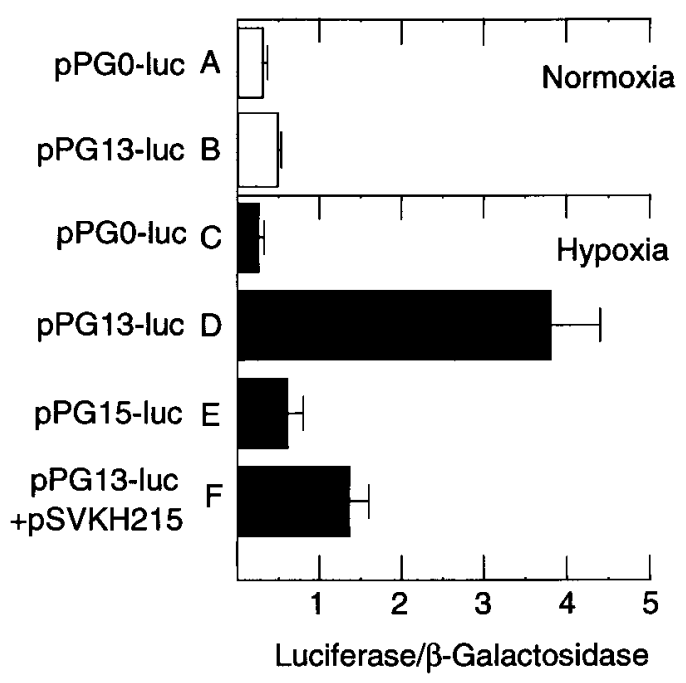

Figure 3. Hypoxia increases p53-mediated transactivation in cultured neonatal cardiac myocytes. Myocytes were transfected with pGL2-0 (basic) alone ( $A$ and $C$ ), pPG13-luc ( $B$ and $D)$, pMG15-luc $(E)$, or pSVKH215 plus pPG13-luc $(F)$. All cultures were cotransfected with pRSV- $\beta$ gal to normalize variations in transfection efficiencies between experiments. Cultures were harvested $48 \mathrm{~h}$ after exposure to normoxic $(A$ and $B)$ or hypoxic $(C-F)$ conditions and analyzed for luciferase and $\beta$-galactosidase activity. Values reported are the mean for at least three independent experiments and are expressed as luciferase activity normalized to $\beta$-galactosidase activity.

a well-characterized target of p53 SST (17) (Fig. 4). This increase in p21/WAF-1/cip-1 mRNA levels was observed as early as $12 \mathrm{~h}$ after imposition of hypoxia and persisted for up to $48 \mathrm{~h}$.

To determine if the increase in p53 SST with hypoxia was due to increased steady state levels of p53 protein in the cells, Western blotting of total cellular extracts was performed. As shown in Fig. 5, $A$ and $B$, increased p53 protein levels could be detected as early as $6 \mathrm{~h}$ after transfer to the hypoxia chamber. Expression remained elevated in the hypoxia treated cultures

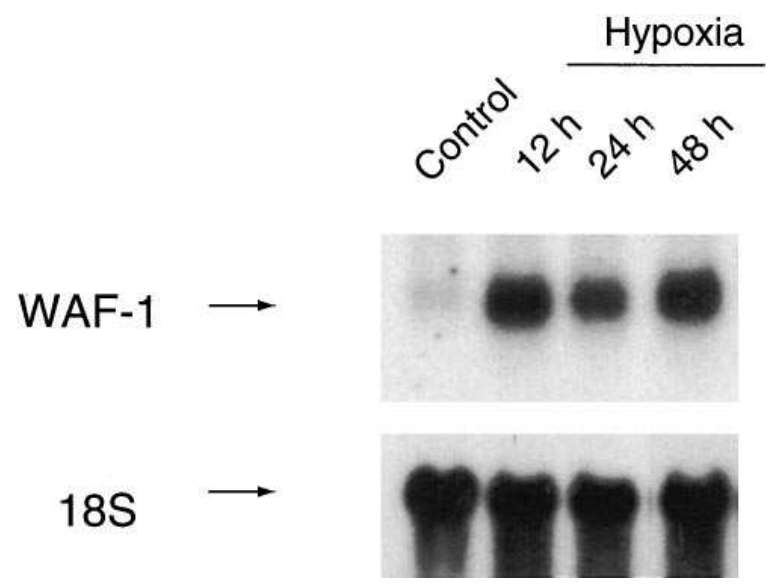

Figure 4. Hypoxia activates expression of p21/WAF1/cip-1 mRNA expression in cultured neonatal cardiomyocytes exposed to hypoxia. Representative Northern blot of p21/WAF1/cip-1 mRNA and 18S rRNA expression in hypoxic and normoxic neonatal cardiomyocyte cell cultures. $10 \mu \mathrm{g}$ of total RNA was loaded in each lane. When normalized to $18 \mathrm{~S}$ rRNA, the increase in p21/WAF1/cip1 mRNA accumulation was five- to sixfold. Results are representative of three independent experiments.

for $18-24 \mathrm{~h}$ but returned to baseline by $48 \mathrm{~h}$. Together with the transfection data on increased SST, these results demonstrate that exposure of cultured neonatal cardiomyocytes to hypoxia increases the expression of functionally active p53.

To examine the significance of increased p53 activity in response to hypoxia, we determined whether overexpression of p53 is sufficient to induce apoptosis in normoxic cardiomyocytes. Myocytes were infected with a replication-defective adenovirus encoding human wild-type p53 under the transcriptional control of the cytomegalovirus promoter (AdCMV.p53). For control, the myocytes were also infected with a replication-defective adenovirus containing an empty expression cassette (AdCMV.null). Infection efficiency was determined by $\beta$-galactosidase staining after infection with AdCMV.NLS $\beta$ gal

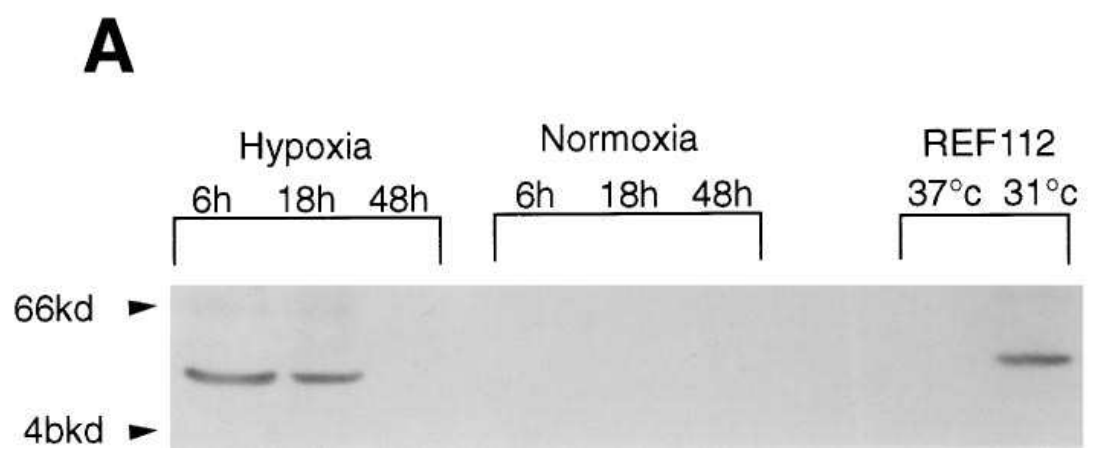

p53

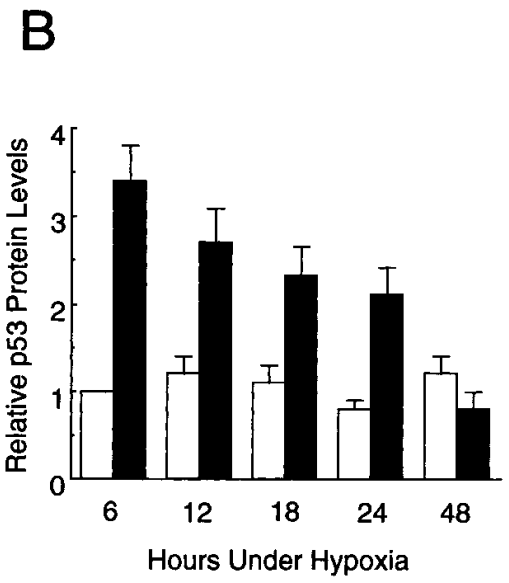

Figure 5. Expression of p53 protein in normoxic and hypoxic cardiomyocyte cultures. $(A)$ Representative Western blot of total cellular protein extracts analyzed for expression of p53 using a pantropic antibody to 33 (Ab421). Extracts from REF112 cells grown at the permissive $\left(31^{\circ} \mathrm{C}\right)$ and restrictive $\left(37^{\circ} \mathrm{C}\right)$ temperature for expression of a stably transfected mutant p53 were used as controls for the reaction. $(B)$ Quantitative analysis of relative p53 protein levels in myocytes under normoxia $(\square)$ and hypoxia $(\boldsymbol{\square})$ as a function of time. The data for each time point represent at least three independent determinations. 


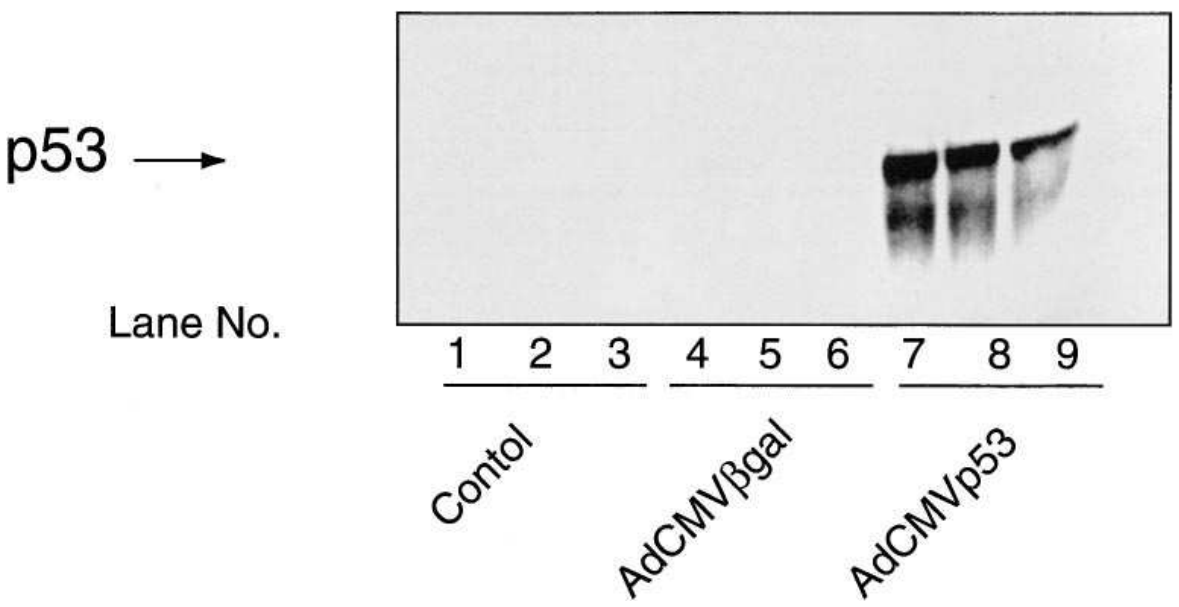

Figure 6. Expression of human $\mathrm{p} 53$ protein in cardiomyocytes after infection with the replication-defective adenovirus, AdCMV.p53. Protein extracts from uninfected cultures (lanes 1-3), AdCM.nullinfected (lanes 4-6), and AdCMV.p53infected (lanes 7-9) cultures were analyzed by Western blotting for expression of human $\mathrm{p} 53$ protein. The three different lanes represent extracts from three different experiments. at a multiplicity of infection (virus particles/cells) of 10 and was observed to be $>95 \%$ at $48 \mathrm{~h}$. Successful infection of the cultures with AdCMV.p53 and the subsequent accumulation of human wild-type p53 protein in rat cardiomyocytes was verified by Western blotting using a human p53-specific antibody (Fig. 6). Significant DNA fragmentation was observed at $48 \mathrm{~h}$ after infection in cardiomyocytes infected with AdCMV.p53, but not in control cells infected with AdCMV.null (Fig. 7 A). At $48 \mathrm{~h}$ after infection, $86.4 \%$ of the cells were TUNEL positive, while only $4.3 \%$ of untreated myocytes or $4.9 \%$ of AdCMV.null-infected myocytes were TUNEL positive (Fig. 7 B). No DNA laddering was observed in cardiac fibroblasts in response to either hypoxia or infection with AdCMV.p53 (Fig. 8). In addition, AdCMV.p53 cardiomyocytes showed significant cell shrinkage or rounding and detachment from the tissue culture surface at $48 \mathrm{~h}$ after infection (Fig. 9, $E$ and $F$ ), while uninfected or AdCMV.null-infected myocytes did not (Fig. 9, $A-D$, respectively). Fig. 10 shows a representative confocal image of the staining for human p53 protein and endlabeled DNA in AdCMV.p53 $(A$ and $B)$ and AdCMV.null infected cells $(C$ and $D)$. Staining for human p53 was detected with a human-specific antibody and a secondary antibody conjugated to Texas red, while end-labeled DNA was detected with a secondary reagent that was conjugated to fluorescein. Consequently, human p53 is indicated by red staining, while end-labeled DNA is green. Yellow staining is the computerassigned designation for the colocalization of both red and green. These results show that $>90 \%$ of the cells exhibiting end-labeled DNA in the AdCMV.p53-infected cultures also express human p53 protein (Fig. 10, $A$ and $B$ ), while very few AdCMV.null-infected cells (equivalent to that shown in Fig. $7 B$ ) showed increased DNA end-labeling (Fig. 10, $C$ and $D$ ).

A

kbp

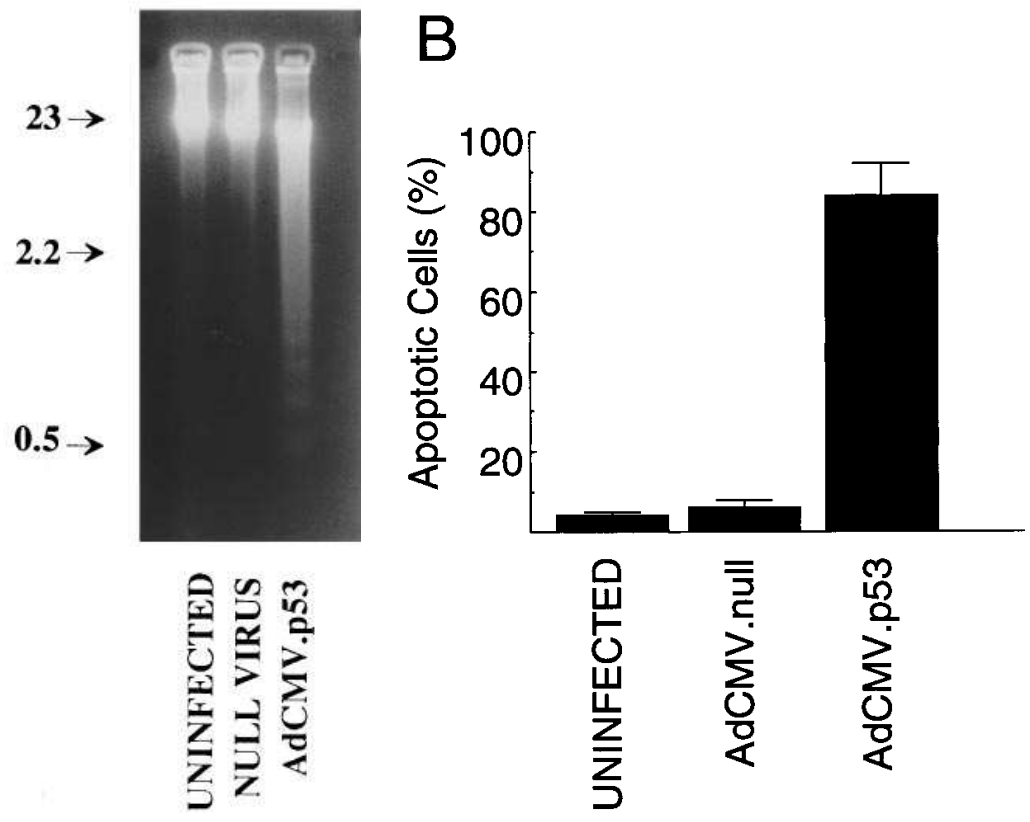

Figure 7. AdCMV.p53 infection induces DNA fragmentation in normoxic cardiomyocytes. $(A)$ DNA fragmentation assay. Genomic DNA was isolated from uninfected (lane 1), AdCMV.nullinfected (lane 2), and AdCMV.p53-infected (lane 3) normoxic cardiomyocyte cell cultures $48 \mathrm{~h}$ after infection and analyzed $(10 \mu \mathrm{g} / \mathrm{lane})$ by gel electrophoresis followed by staining with ethidium bromide. Results are representative of at least three independent experiments. (B) Quantification of results of TUNEL assay performed $48 \mathrm{~h}$ after infection. The data for each condition represent the average of at least four different infections. 


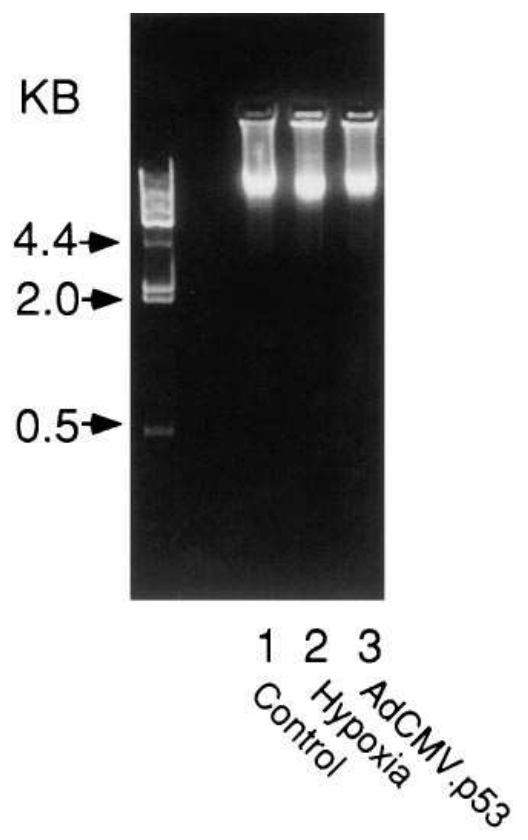

Figure 8. Exposure to hypoxia or infection with AdCMV.p53 does not induce DNA fragmentation in cardiac fibroblasts. Genomic DNA isolated from untreated fibroblasts (lane 1), fibroblasts exposed to $48 \mathrm{~h}$ of hypoxia (lane 2), and fibroblasts infected with AdCMV.p53 for $48 \mathrm{~h}$.

\section{Discussion}

Previous studies by Tanaka and colleagues (13) have demonstrated that exposure of cultured neonatal cardiomyocytes to hypoxia induces apoptotic cell death. Our results show that these cells, which even at this early stage after birth are quiescent and postmitotic, exhibit increased p53 protein levels and SST compared to normoxic controls. Increased p53 SST was evident from the increased expression of a reporter gene driven by p53-specific DNA-binding (Fig. 3), by increased p53 protein expression (Fig. 5), and by increased expression of p21/ WAF-1/cip-1 (Fig. 4), a well-characterized target of p53 transactivation. That such increases in p53 activity are of potential significance is shown by the fact that overexpression of wildtype p53 by adenovirus-mediated gene transfer is sufficient to induce apoptosis in normoxic myocytes (Fig. 7). On the other hand, fibroblasts isolated from the neonatal myocardium and maintained in cell cultures showed no signs of apoptosis after exposure either to hypoxia or the adenovirus encoding wildtype p53 (Fig. 8). Taken together, these findings strongly suggest that p53 plays a critical role in hypoxia-induced apoptosis of cardiac myocytes.

Although small numbers of fibroblasts are present in every culture of neonatal myocytes, the apoptosis that results from either AdCMV.p53-infection or hypoxia is mostly, if not totally, confined to myocytes. This is evident from the facts that the cellular composition of these cultures is $>90 \%$ myocytes (see Methods for techniques used to achieve this level of purity and the assays used to monitor purity) and that $>80 \%$ of the cells show treatment-specific increases in DNA end-labeling (Figs. $2 \mathrm{C}$ and $7 \mathrm{~B}$ ). While some cellular death by apoptosis may be occurring in the $<10 \%$ of the cultured cells which are designated as nonmyocytes or fibroblasts, it is important to note that these cells when cultured on their own do not undergo apoptosis in response to either hypoxia (13) (Fig. 8) or overexpression of p53 (Fig. 8). It is also possible that some of

the cell loss that accompanies hypoxia or p53-overexpression is due to necrosis and not apoptosis.

Studies on the role of $\mathrm{p} 53$ in the regulation of programmed cell death have been almost exclusively confined to actively proliferating cells. Depending on the cell type, the increase in p53 protein levels or transactivating ability which occurs in response to DNA damage can result in either growth arrest or apoptosis. Thus, proliferating skin fibroblasts from p53 homozygous and heterozygous mice undergo growth arrest in response to DNA damage, while differentiated thymocytes undergo apoptosis. However, when isolated from p53 nullizygous mice these same cell types do not undergo either growth arrest or apoptosis in response to DNA damage $(11,12,25)$. These studies have led to the concept of p53 as guardian of the genome (26), its activation leading to either the cessation of DNA replication (growth arrest) long enough to repair genomic DNA or to the death of the cell in order to prevent damageinduced mutations from being incorporated into the genome. The differences in the response of different cells to DNA damaging agents may, in fact, reflect their ability to repair such damage. Thus, the effect of activating p53 in cells which are not capable of extensive proliferation, such as the cardiomyocytes used in this study, is unclear. We have observed that activation of $\mathrm{p} 53$ in cardiomyocytes is associated with cell death by apoptosis. The persistence of the p53 response in quiescent cells such as cardiomyocytes may be a remnant of the guardian response or, alternatively, may indicate that p53 has additional roles in the regulation of cell fate aside from ensuring that mutations associated with DNA damaging agents are not transmitted to daughter cells.

Although there are an estimated 200-300 p53 binding sites in the human genome (27), few targets of p53 SST have been identified. p21/WAF-1/cip-1 is one of the best-characterized targets of p53. It inhibits the function of cyclin-dependent complexes and prevents cell cycle progression $(17,28)$. What role $\mathrm{p} 21 / \mathrm{WAF} 1 / \mathrm{CIP} 1$ plays in cells that are already blocked in cell cycle progression is unclear, but recent studies suggest that it is not involved in the control of apoptosis (29) and may, under some circumstances, block cell death when overexpressed (30). Indeed, recent studies indicate that the SST of genes, such as p21/WAF1/cip-1, by p53 may be more closely linked with the growth-inhibitory rather than the apoptotic-inducing effects of p53 (31). Thus, in some cell types, transactivationdeficient mutants of p53 can still induce apoptosis, although the rate at which this occurs is much slower than with wild-type p53. On the other hand, overexpression of other genes which are transactivated by $\mathrm{p} 53$, such as bax (32), can induce apoptosis in some cell types. How a cell responds to the increased expression of p53 and whether that response results in apoptosis seems to be cell type dependent and dictated by currently undefined events.

Aside from acute ischemia, cardiac myocyte loss also occurs during aging and during the development of heart failure (33-37). Papillary muscles from aged spontaneously hypertensive rats (SHR) which show evidence of heart failure are characterized by a reduction in myocyte fractional area and a corresponding increase in the fractional area occupied by extracellular matrix, as compared to those from aged-matched nonfailing myocardium (38). Apoptotic nuclei have been detected recently in the failing hearts of aged SHR (39), and active $\mathrm{p} 53$ has been detected in the infarcted regions of dogs with chronic heart failure, while only p53 in its inactive confor- 


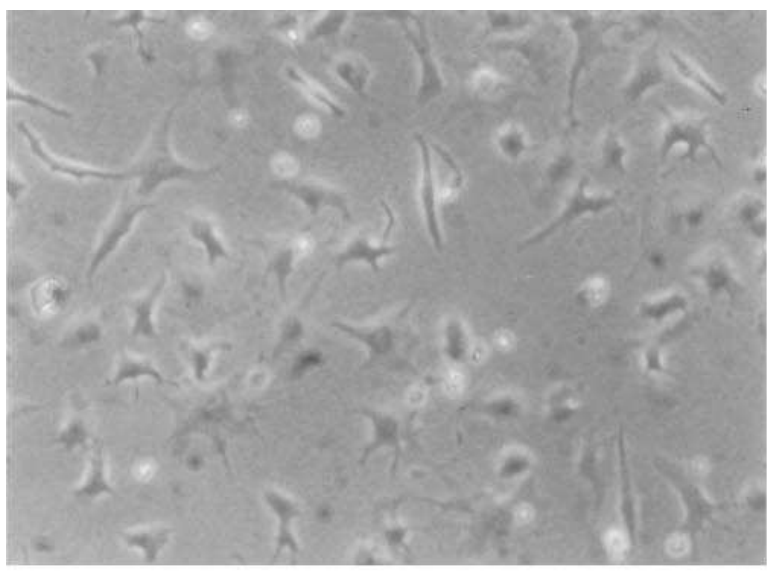

\section{A. Uninfected, 125X}

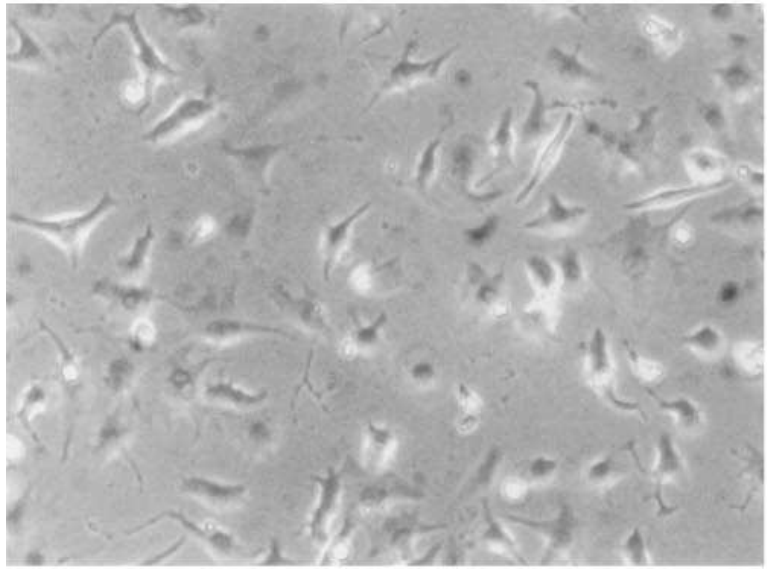

C. AdCMV.null, 125X

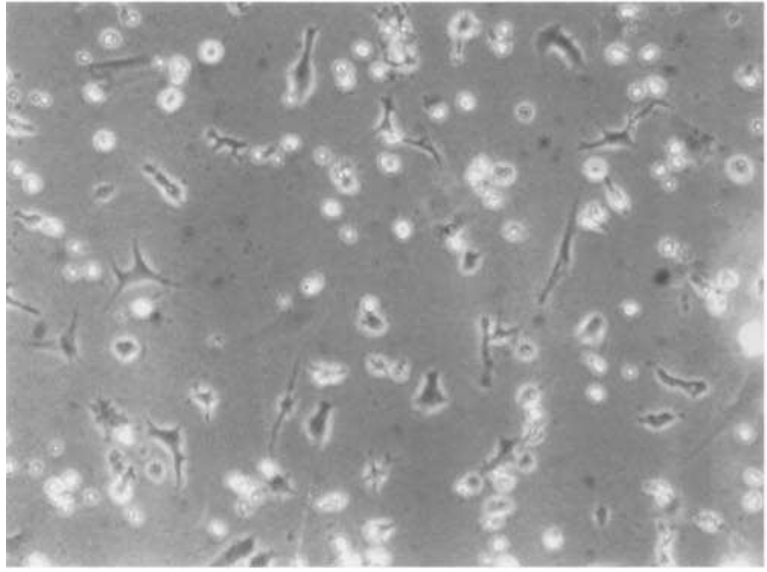

\section{E. AdCMV.p53, 125X}

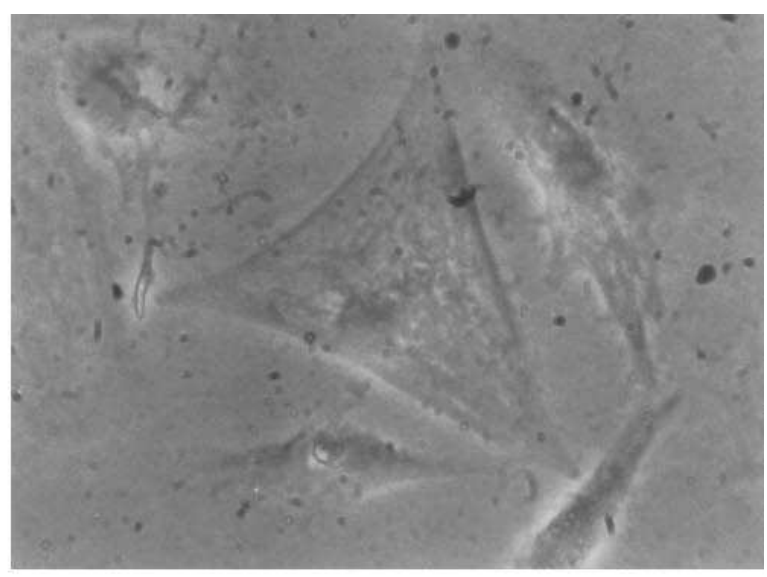

\section{B. Uninfected, 400X}

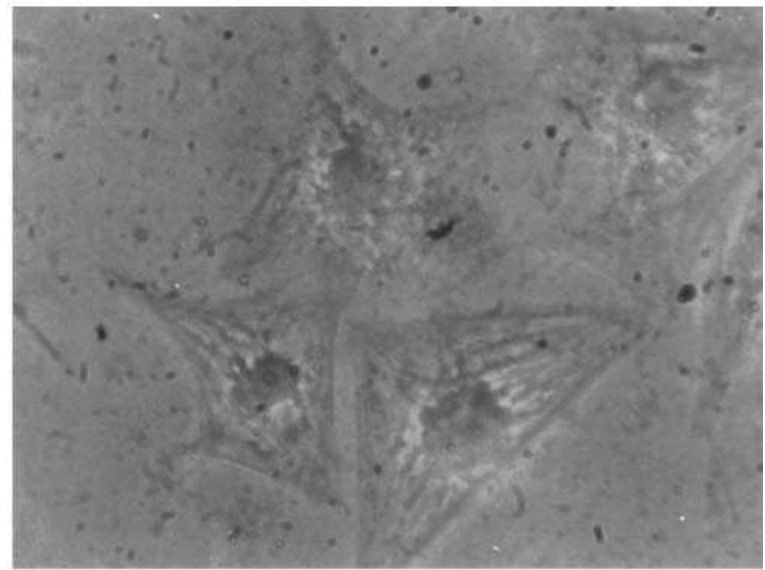

\section{AdCMV.null, 400X}

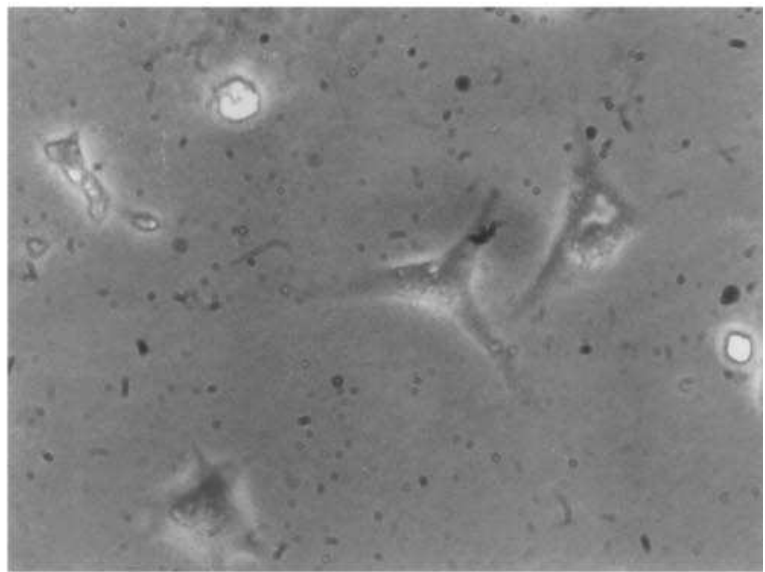

\section{F. AdCMV.p53, 400X}

Figure 9. Morphological changes induced by AdCMV.p53 infection. Low and high power phase-contrast photomicrographs of uninfected $(A$ and $B$ ), AdCMV.null-infected ( $C$ and $D$ ), and AdCMV.p53-infected ( $E$ and $F$ ) cells $48 \mathrm{~h}$ after infection. 


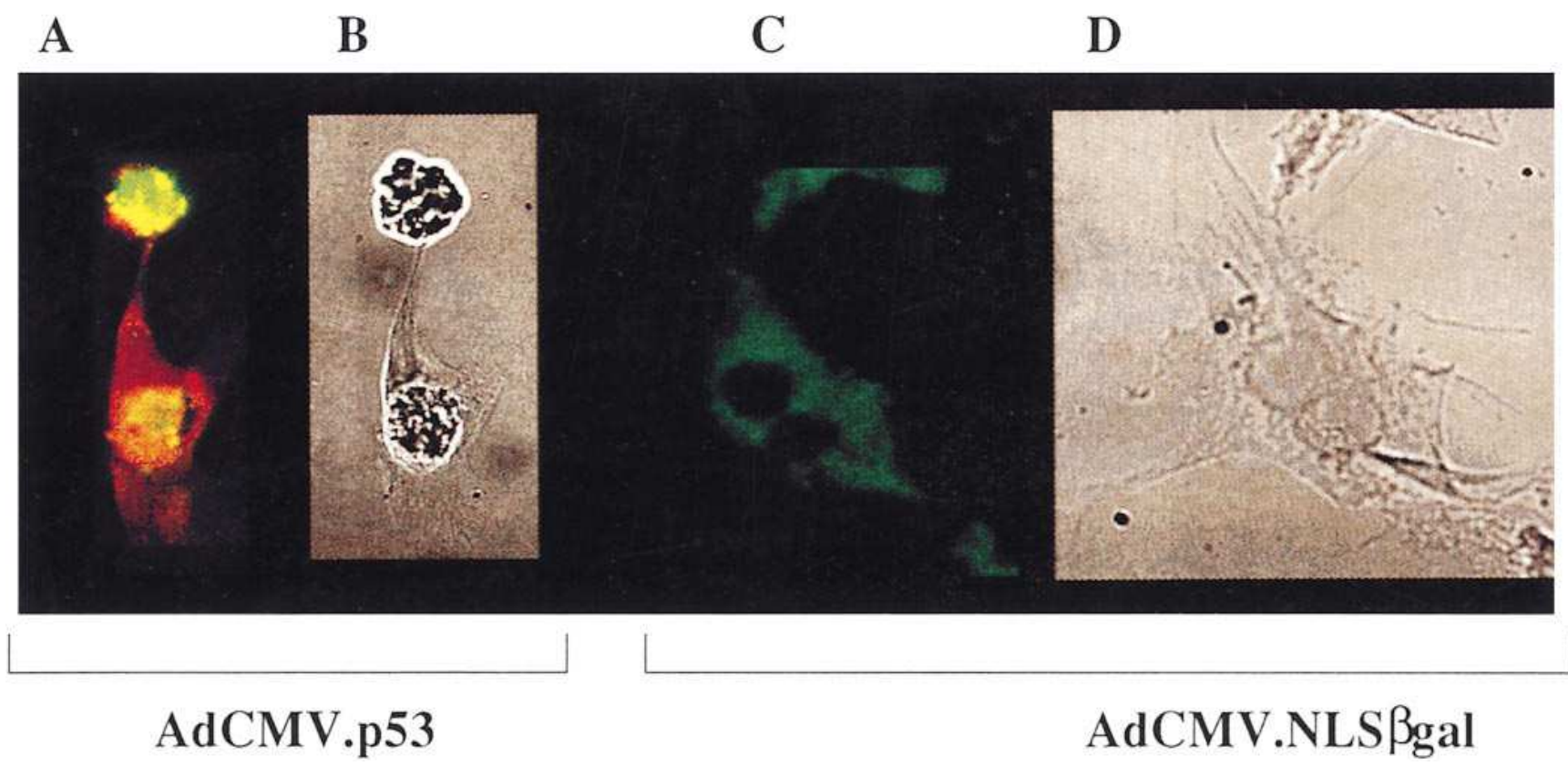

Figure 10. Colocalization of human 553 protein and apoptotic DNA cleavage in cardiomyocytes infected with AdCMV.p53. Cardiomyocyte cultures infected with AdCMV.p53 ( $A$ and $B$ ) or AdCMV.NLSßgal $(C$ and $D$ ) were stained with an antibody specific for human p53 and then treated for detection of end-labeled DNA using the TUNEL technique. Human p53 protein and end-labeled DNA were then detected with either a secondary antibody conjugated to Texas red and fluorescein, respectively. Structures staining for p53 alone are red, for end-labeled DNA alone (green), and for both $\mathrm{p} 53$ and end-labeled DNA (yellow). In $A$, yellow staining in the nucleus demonstrates colocalization of p53 and endlabeled DNA.

mation could be detected outside this region (40). Since the functional aspects of the failing myocardium may be impaired in proportion to the reduction in myocyte fractional area (37), it is possible that apoptosis plays a major role in the deterioration of pump function and that activation of p53 may be important to the signaling mechanism responsible for programmed cell death.

Hypoxia-treated cultured neonatal cardiomyocytes are a useful experimental system to define the intracellular pathways responsible for apoptosis in response to physiological stress, particularly with respect to the role of $\mathrm{p} 53$. It remains to be determined if p53 is necessary for hypoxia-induced myocyte apoptosis and whether p53 SST or other aspects of p53's effects on gene regulation are involved in the apoptotic response of cardiomyocytes. One approach will be to determine if the response to ischemia is altered in hearts from p53 knockout mice or if levels of ischemia-induced apoptosis are reduced in these animals (41). It will also be of interest to determine if other stimuli for apoptosis of cardiomyocytes also evoke increased p53 or p21 expression and whether overexpression of p21 can block or stimulate apoptosis.

\section{Acknowledgments}

The authors express their gratitude to Drs. Wafik El-Diery and Bert Vogelstein (Johns Hopkins University) for supplying the PG13 and MG15 luciferase reporter constructions, the p53 adenovirus, and the p21/WAF-1 cDNA; to Dr. Arnold Levine (Princeton University) for the expression vector for mutant (dominant negative) p53; to Maurizio C. Capogrossi for providing facilities for preparing the adenoviruses; and to Steven Sollott, Dennis Rozanski, and Hal Spurgeon (NIA) for assistance on confocal imaging.

\section{References}

1. Pfeffer, M.A., and E. Braunwald. 1990. Ventricular remodeling after myocardial infarction. Circulation. 81:1161-1172.

2. Gottlieb, R.A., K.O. Burleson, R.A. Kloner, B.M. Babior, and R.L. Engler. 1994. Reperfusion injury induces apoptosis in rabbit cardiomyocytes. $J$. Clin. Invest. 94:1621-1628.

3. Kajstura, J., W. Cheng, K. Reiss, W.A. Clark, E.H. Sonnenblick, S. Krajewski, J.C. Reed, G. Olivetti, and P. Anversa. 1996. Apoptotic and necrotic myocyte cell deaths are independent contributing variables of infarct size in rats. Lab. Invest. 74:86-107.

4. Wyllie, A.H. 1980. Glucocorticoid-induced thymocyte apoptosis is associated with endogenous endonuclease activation. Nature (Lond.). 284:555-556.

5. Majno, G., and I. Joris. 1995. Apoptosis, oncosis, and necrosis: an overview of cell death. Am. J. Pathol. 146:3-15.

6. Thompson, C.B. 1995. Apoptosis in the pathogenesis and treatment of disease. Science (Wash. DC). 267:1456-1462.

7. Baker, S.J., E.R. Fearon, J.M. Nigro, S.R. Hamilton, A.C. Preisinger, J.M. Jessup, P. van Tuinen, D.H. Ledbetter, D.F. Barker, Y. Nakamura, et al. 1989. Chromosome 17 deletions and p53 gene mutations in colorectal carcinomas. Science (Wash. DC). 44:217-221.

8. Yonish-Rouach, E., D. Resnitsky, J. Lotem, L. Sachs, A. Kimchi, and M. Oren. 1991. Wild-type p53 induces apoptosis of myeloid leukemia cells that is inhibited by interleukin-6. Nature (Lond.). 352:345-347.

9. Gottlieb, E., R. Haffner, T. von Rudin, E.F. Wagner, and M. Oren. 1994 Down-regulation of wild-type p53 activity interferes with apoptosis of IL-3dependent hematopoietic cells following IL-3 withdrawal. EMBO (Eur. Mol. Biol. Organ.) J. 13:1368-1374.

10. Zhan, Q., F. Carrier, and A.J. Fornace. 1993. Induction of cellular p53 activity by DNA-damaging agents and growth arrest. Mol. Cell. Biol. 13:42424250 .

11. Kastan, M.B., Q. Zhan, W.S. El-Deiry, F. Carrier, T. Jacks, W.V. Walsh, B.S. Plunkett, B. Vogelstein, and A.J. Fornace. 1992. A mammalian cell cycle checkpoint pathway utilizing p53 and GADD45 is defective in ataxia-telangiectasia. Cell. 13:587-597.

12. Lowe, S.W., E.M. Schmitt, S.W. Smith, B.A. Osborne, and T. Jacks. 1993. p53 is required for radiation induced apoptosis in mouse thymocytes. $\mathrm{Na}$ ture (Lond.). 362:847-849.

13. Tanaka, M., H. Ito, S. Adachi, H. Akimoto, T. Nishikawa, T. Kasajima, F. Marumo, and M. Hiroe. 1994. Hypoxia induces apoptosis with enhanced expression of Fas antigen messenger RNA in cultured neonatal rat cardiomyo- 
cytes. Circ. Res. 75:426-433.

14. Zheng, J.S., M.O. Boluyt, L. O'Neill, M.T. Crow, and E.G., Lakatta. 1994. Extracellular ATP induces immediate early gene expression but not cellular hypertrophy in neonatal cardiac myocytes. Circ. Res. 74:1034-1041.

15. Prigent, P., C. Planpied, J. Aten, and F. Hirsch. 1993. A safe and rapid method for analyzing apoptosis-induced fragmentation of DNA extracted from tissue or cultured cells. J. Immunol. Methods. 160:139-140.

16. Xu, H., J. Miller, and B.T. Liang. 1992. High-efficiency gene transfer into cardiac myocytes. Nucl. Acids Res. 20:6425-6426.

17. El-Deiry, W.S., T. Tokino, V.E. Velculescu, D.B. Levy, R. Parsons, J.M. Trent, D. Lin, W.E. Mercer, K.W. Kinzler, and B. Vogelstein. 1993. WAF-1, a potential mediator of p53 tumor suppression. Cell. 75:817-825.

18. Tan, T.H., J. Wallis, and A.J. Levine. 1986. Identification of the p53 protein domain involved in formation of the simian virus 40 large $\mathrm{T}$ antigen-p53 protein complex. J. Virol. 59:574-583.

19. Chirgwin, J.M., A.E. Przybyla, R.J. MacDonald, and W.J. Rutter. 1979. Isolation of biologically active ribonucleic acid from sources enriched in ribonuclease. Biochemistry. 18:5294-5299.

20. Church, G.M., and W. Gilbert. 1984. Genomic sequencing. Proc. Natl. Acad. Sci. USA. 81:1991-1995.

21. Feinberg, A.P., and B. Vogelstein. 1983. A technique for radiolabeling DNA restriction endonuclease fragments to high specific activity. Anal. Biochem. 132:6-13.

22. O'Neill, L., N.J. Holbrook, J. Fargnoli, and E.G. Lakatta. 1991. Progressive changes from young adult age to senescence in mRNA for rat cardiac myosin heavy chain genes. Cardioscience. 2:1-5.

23. Brett, A.J., W. Haddara, L. Prevec, and F.L. Graham. 1994. An efficient and flexible system for construction of adenovirus vectors with insertions or deletions in early regions 1 and 2. Proc. Natl. Acad. Sci. USA. 91:8802-8806.

24. Kass-Eisler, A., E. Falck-Pedersen, M. Alvira, J. Rivera, P.M. Buttrick, B.M. Wittenberg, L. Cipriani, and L.A. Leinwand. 1993. Quantitative determination of adenovirus-mediated gene delivery to rat cardiac myocytes in vitro and in vivo. Proc. Natl. Acad. Sci. USA. 90:11498-11502.

25. Clarke, A.R., C.A. Purdie, D.J. Harrison, R.G. Morris, C.C. Bird, M.L. Hopper, and A.H. Wyllie. 1993. Thymocyte apoptosis induced by p53-dependent and independent pathways. Nature (Lond.). 362:849-852.

26. Lane, D.P. 1992. p53, guardian of the genome. Nature (Lond.). 358:15-16.

27. Tokino, T., S. Thigalingam, W.S. El-Diery, T. Wladman, K.W. Kinzler, and B. Vogelstein. 1994. p53 tagged sites from the human genome. Hum. Mol. Genet. 3:1537-1542.

28. Harper, J.W., G.R. Adami, N. Wei, K. Keyomarsi, and S.J. Elledge.
1993. The p21 Cdk-interacting protein Cip1 is a potent inhibitor of Gi cyclindependent kinases. Cell. 75:805-816.

29. Katayose, D., R. Wersto, K.H. Cowan, and P. Seth. 1995. Effects of a recombinant adenovirus expressing WAF1/Cip1 on cell growth, cell cycle, and apoptosis. Cell Growth Differ. 6:1207-1212.

30. Canman, C.E., T.M. Gilmer, S.B. Coutts, and M.B. Kastan. 1995 Growth factor modulation of p53-mediated growth arrest versus apoptosis. Genes Dev. 9:600-611.

31. Haupt, Y., S. Rowan, E. Shaulian, K.H. Vousden, and M. Oren. 1995. Induction of apoptosis in HeLa cells by transactivation-deficient p53. Genes Dev. 9:2170-2183.

32. Miyashita, T., and J.C. Reed 1995. Tumor suppressor p53 is a direct transcriptional activator of the human bax gene. Cell. 80:293-299.

33. Anversa, P., B. Hiler, R. Ricci, G. Guideri, and G. Olivetti. 1986. Myocyte cell loss and myocyte hypertrophy in the aging rat heart. J. Am. Coll. Cardiol. 8:1441-1448.

34. Anversa, P., T. Palackai, E.H. Sonnenblick, G. Olivetti, L.G. Meggs, and J.M. Capasso. 1990. Myocyte cell loss and myocyte hyperplasia in the hypertrophied aging rat heart. Circ. Res. 67:871-885.

35. Liu, Y., E. Cigola, W. Cheng, J. Kajstura, G. Olivetti, T.H. Hintze, and P. Anversa. 1995. Myocyte nuclear mitotic division and programmed cell death characterize the cardiac myopathy induced by rapid ventricular pacing in dogs. Lab. Invest. 73:771-787.

36. Lakatta, E.G. 1993. Cardiovascular regulatory mechanisms in advanced age. Physiol. Rev. 73:413-467.

37. Bing, O.H.L. 1994. Hypothesis: apoptosis may be a mechanism for the transition to heart failure with chronic pressure overload. J. Mol. Cell. Cardiol. 26:943-948.

38. Conrad, C.H., W.W. Brooks, J.A. Hayes, S. Sen, K.G. Robinson, and O.H.L. Bing. 1995. Myocardial fibrosis and stiffness with hypertrophy and heart failure in the spontaneously hypertensive rat. Circulation. 91:161-170.

39. Li, Z., E.G. Lakatta, K.G. Robinson, and O.H.L. Bing. 1997. Detection of apoptosis in the failing hearts of spontaneously hypertensive rats. Amer. J. Physiol. In press.

40. Sharov, V.G., H.N. Sabbah, A.V. Goussev, M. Lesch, and S. Goldstein. 1995. Increased expression of apoptosis associated p53 protein in cardiomyocytes of dogs with chronic heart failure. Circulation. 92:I525a. (Abstr.)

41. Donehower, L.A., M. Harvey, B.L Slagle, M.J. McAurthur, C.A. Montgomery, J.S. Butle, and A. Bradley. 1992. Mice deficient for p53 are developmentally normal but susceptible to spontaneous tumors. Nature (Lond.). 356: 215-221. 